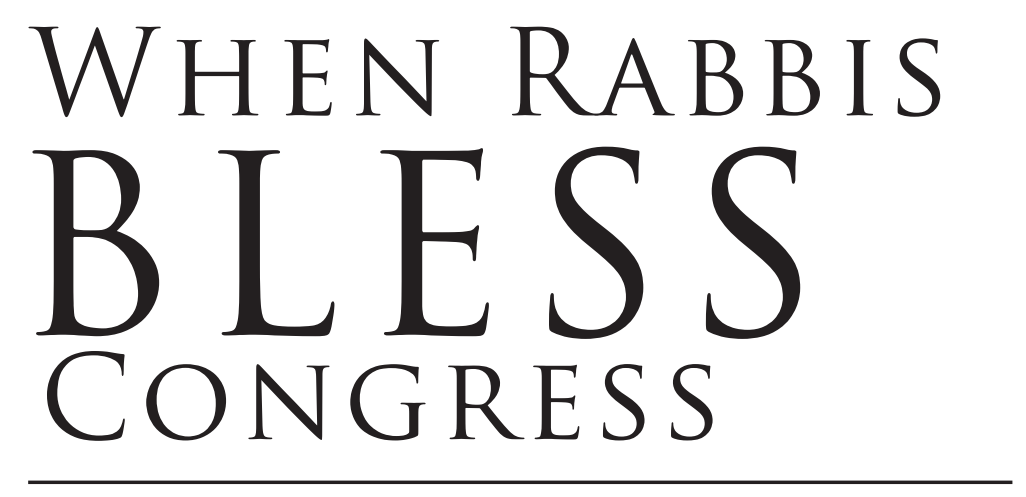

The Great American Story of Jewish Prayers on Capitol Hill 
ลัก

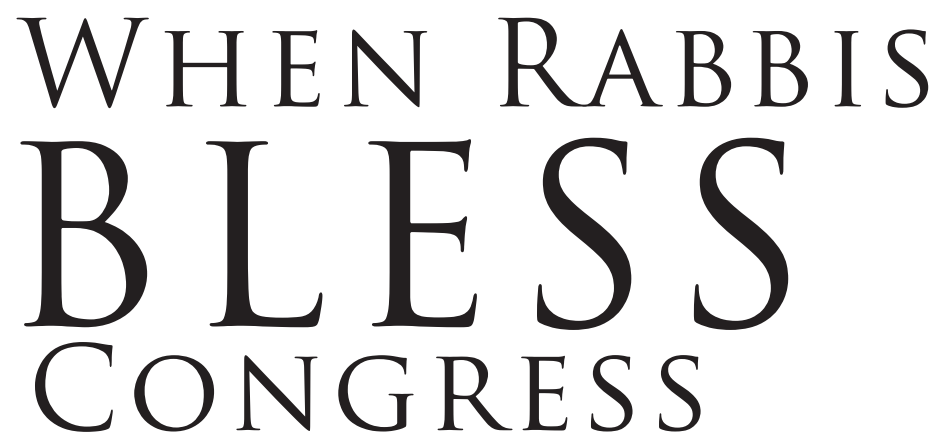

The Great American Story of Jewish Prayers on Capitol Hill

BY HOWARD MORTMAN 


\section{On the cover:}

Top row, left to right: Bruce Lustig, Mara Nathan, Gary Zola, Laszlo Berkowitz Second row, left to right: Arnold Resnicoff, Abraham De Sola, Harold Robinson, Levi Shemtov

Third row, left to right: Gil Steinlauf, Ellen Wolintz-Fields, Steven Rein, Amy Rader

Bottom row, left to right: Mark Getman, Hannah Spiro, Gershon Avtzon, Romi Cohn

\section{Library of Congress Cataloging-in-Publication Data}

Names: Mortman, Howard, 1967- author.

Title: When rabbis bless Congress : the great American story of Jewish prayers on Capitol Hill / Howard Mortman.

Description: Boston : Cherry Orchard Books, October 2020.

Identifiers: LCCN 2020019048 (print) | LCCN 2020019049 (ebook) | ISBN 9781644693438 (hardback) | ISBN 9781644693445 (paperback) | ISBN 9781644693452 (adobe pdf)

Subjects: LCSH: Legislative bodies--Chaplains' prayers. | United States. Congress--Chaplains. | Rabbis--United States. | Jews--United States--Politics and government. | Capitol Hill (Washington, D.C.)--Religious life and customs. | United States--Ethnic relations.

Classification: LCC BV280 .M77 2020 + (print) | LCC BV280 (ebook) | DDC 296.4/509753--dc23

LC record available at https://lccn.loc.gov/2020019048

LC ebook record available at https://lccn.loc.gov/2020019049

Copyright (C) 2020 Academic Studies Press. All rights reserved.

ISBN 9781644693438 (hardback); ISBN 9781644693445 (paperback); ISBN 9781644693452 (adobe pdf); ISBN 9781644693469 (ePub)

Book design by Lapiz Digital Services. Cover design by Kate Connolly. Published by Cherry Orchard Books, an imprint of Academic Studies Press 1577 Beacon Street Brookline, MA 02446, USA press@academicstudiespress.com | www.academicstudiespress.com 